$\begin{array}{cc}\text { Türkiye Tarımsal Araştırmalar Dergisi } & \text { Turk J Agric Res } \\ \text { http://dergi.siirt.edu.tr } & \text { (2016) 3: 64-73 } \\ \text { OC TÜTAD } & \text { ISSN: 2148-2306 } \\ \text { Adoi: 10.19159/tutad.90748 }\end{array}$

\title{
Aşağı Büyük Menderes ve Aşağı Gediz Havzası Sulama Birliklerinin Üretim ve Su Kullanım Performanslarının Karşılaştırmalı Olarak Değerlendirilmesi
}

\author{
Selin AKÇAY*, Safiye Pınar TUNALI \\ Adnan Menderes Üniversitesi, Ziraat Fakültesi, Biyosistem Mühendisliği Bölümü, Aydın, TÜRKIYE
}

\begin{abstract}
Geliş Tarihi/Received: 25.01 .2016
Kabul Tarihi/Accepted: 06.03.2016

"Sorumlu yazar/Corresponding author: selinakcay@adu.edu.tr

Özet: Belirli bir sulama sisteminin mevcut performansının kendisiyle benzer özellikler gösteren sulama sistemlerinin performansı ile karşılaştırılarak değerlendirilmesi, sulama sistemlerinde hedeflenen amaçlara ne düzeyde ulaşılabildiğinin ortaya konmasında kullanılmaktadır. Bu çalışmada karşılaştırmalı değerlendirme gösterge setinden seçilen bitkisel üretim ve su temini göstergeleri kullanılarak, Așağı Büyük Menderes Havzası'nda yer alan Akçay Sağ ve Sol Sahil Sulama Birlikleri, Aydın Ovası ve Söke Ovası Sulama Birliği ile Aşağı Gediz Havzası'nda yer alan Menemen Sağ ve Sol Sahil Sulama Birliklerinin performansları değerlendirilmiștir. Değerlendirilen yıllar için sulama birliklerinin ortalaması, proje alanı bitkisel üretim değeri için 1707-2824 \$ ha ${ }^{-1}$, sulanan alan bitkisel üretim değeri için 2048-3414 $\$$ ha $^{-1}$, saptırılan birim suya karşıllk bitkisel üretim değeri için $0.30-0.60 \$ \mathrm{~m}^{-3}$, bitki su tüketimine karşılık bitkisel üretim değeri için 0.27-0.46 $\$ \mathrm{~m}^{-3}$ olarak belirlenmiştir. Su temin oranı ortalama değeri 1.02-1.60; sulama suyu sağlama oranı ortalama değeri $0.62-0.95$ aralığında değişirken, birim sulanan alana düşen su miktarı ortalama değeri 5965-11043 $\mathrm{m}^{3} \mathrm{ha}^{-1}$ aralı̆ğnda gerçekleşmiştir. Calışma sonucunda; özellikle su kullanım etkinliğine ilișkin göstergelerde sorunlar yaşandığı saptanmıș, bitkisel üretim değerlerinin ise benzer özellik gösteren sulama sistemlerindekine oranla daha yüksek düzeyde olduğu belirlenmiştir.
\end{abstract}

Anahtar Kelimeler: Performans değerlendirme, performans göstergesi, sulama birliği, su temini, üretim performans1

\section{Comparative Evaluation of Productivity and Water Supply in Lower Büyük Menderes and Lower Gediz Basin Water User Associations}

\begin{abstract}
Comparative analysis of irrigation performance across irrigation systems allows determining how well a system is performing in relation to others. In this research, Akçay Right and Left Bank, Aydın and Söke Water User Associations located in Lower Büyük Menderes Basin and Menemen Right and Left Bank Water User Associations located in Lower Gediz Basin were assessed by using benchmarking applications in irrigation and drainage. As a result of the study, output per cropped area, output per unit command, output per unit irrigation supply, output per unit water consumed, relative water supply, relative irrigation supply and annual irrigation water delivery per unit irrigated area were determined as 2048-3414 \$ $\mathrm{ha}^{-1}, 1707-2824 \$ \mathrm{ha}^{-1}, 0.30-0.60 \$ \mathrm{~m}^{-3}, 0.27-0.46 \$ \mathrm{~m}^{-3}, 1.02-1.60,0.62-0.95$ and $5965-11043 \mathrm{~m}^{3} \mathrm{ha}^{-1}$ respectively. The main problems determined by this study are the improper use of water and inadequate water allocation especially to the downstream water user associations. Agricultural production values of the water user associations are relatively higher than those having similarities and similar functions.
\end{abstract}

Keywords: Performance evaluation, performance indicators, water user association, water supply, production performance

\section{Giriş}

Günümüzde, artan nüfusun ve gelişen modern dünyanın en önemli sorunu hızla tüketilen doğal kaynaklardır. Bu nedenle doğal kaynaklar en iyi şekilde korunarak, tarımsal üretimin en üst düzeye çıkartılması büyük önem taşımaktadır. Bu durum, 
su kaynakları yönetiminde, yeni teknolojilerin geliştirilmesi ve yeni yönetim stratejilerinin uygulanmasını gerekli kılmaktadır.

Sulu tarımın performansını arttırıcı önlemlerin yetersizliği nedeniyle, mevcut potansiyelinin çok altında hizmet veren sulama sistemlerinden beklenen faydalar elde edilememektedir. Çözüm olarak her sistem izlenip, etkinlikleri değerlendirildikten sonra, gerekli iyileştirme ve geliştirmeler yapılarak, sulama projelerinden beklenen faydaların gerçekleşmesi sağlanabilir.

Performans değerlendirmesi değişik amaçlar için yapılır. Bu amaçlar; sistemin iyileştirilmesi, sistemin genel durumunun ve sisteme yapilan müdahalelerin etkilerinin ve sistemi zorlayan unsurların belirlenmesi ile sistemin kendi içerisinde yıllara göre karşılaştırılması ve bir sistemin diğerleriyle karşılaştırılması şeklinde sıralanabilir (Molden ve ark., 1998).

İlk kez, Molden ve ark. (1998) tarafindan ortaya konan ve farklı sulama sistemlerinin birbiriyle karşılaştırılmasına olanak tanıyan Uluslararası Su Yönetimi Enstitüsü (International Water Management Institute, IWMI) dişsal performans gösterge seti, sulama sistemlerinde karşılaştırma uygulamasının ilk adımı olarak değerlendirilebilir. 1999 yılında Dünya Bankası'nın girişimi ve Sulama ve Drenajda Uluslararası Teknoloji ve Araştırma Programı (International Program Technology and Research in Irrigation and Drainage, IPTRID) öncülüğünde bir grup örgütün ortak çalışmaları sonucunda sulama ve drenaj sistemlerinin performansının karşılaştırmalı değerlendirilmesi için bazı yaklaşımlar önerilmiştir. Malano ve Burton (2001) tarafindan bu çalışmalar sonucunda belirlenen temel ilkeler ve göstergeler ortaya konmuştur. Bu göstergeler ile sulama ve drenaj yönetiminde; çevresel ve ekonomik performans, üretim etkinliği ve su dağıtım hizmetlerinin etkinliği gibi farklı açılardan yaklaşım ve değerlendirmeler yapılmaktadır. $\mathrm{Bu}$ yöntemin temel amacı, belirli bir sulama sisteminin performansının kendisine benzer özellikler taşıyan diğer sulama sistemiyle karşılaştırılması ve böylelikle hangi uygulamalar ile daha yüksek performansa ulaşılabileceğinin ortaya konmasıdır (Gonzalez, 2000; RodríguezDíaz ve ark., 2004).

İşletme-Bakım-Yönetim (İBY) sorumluluğu kamu kurumlarında iken, sulama birlikleri ya da sulama kooperatifleri gibi örgütlere devri gerçekleşen sulama sistemlerinde izleme ve değerlendirme çalışmaları, sulu tarıma yapılan yatırımların geri dönüşümünün sağlanmasında büyük öneme sahiptir. Buna karşın ülkemiz sulama sistemlerinde işletme aşamasında performans değerlendirme çalışmaları ancak son 20 yıldır etkin bir șekilde uygulanmaktadır. Bu konudaki çalışmalar son yillarda giderek artmakta ve birçok araştırmacı sulama sistemlerinin daha iyi yönetilebilmesi için öneriler sunmaktadır (Molden ve Gates,1990; Small ve Svendsen, 1992; MurrayRust ve Snellen, 1993; Rao, 1993; Bos, 1997). Bu çalışma ile, sulama birliklerinde devir sonrası hedeflerin gerçekleşme oranlarının belirlenmesi amaçlanmıştır. Çalışmadan elde edilen sonuçlara göre önemli tarımsal potansiyele sahip olan iki havzada yer alan sulama birliklerinin yönetiminde görülen zayıf ve kuvvetli yönler ortaya konarak, daha etkin bir sulama yönetiminin sağlanabilmesi için öneriler getirilmiştir. Bu yolla, son yıllarda giderek azalan su kaynaklarımızdan tarımsal sulamada daha verimli şekilde yararlanılabilmesi mümkün olacaktır.

\section{Materyal ve Yöntem}

\subsection{Araştırma yerinin genel tanımı ve iklim özellikleri}

$\mathrm{Bu}$ çalışmada; Aşağı Büyük Menderes Havzası'nda yer alan, Akçay Sağ Sahil Sulama Birliği ve Akçay Sol Sahil Sulama Birliği, Aydın Ovası Sulama Birliği ve Söke Ovası Sulama Birliği ile Aşağı Gediz Havzası'nda yer alan, Menemen Sağ ve Sol Sahil Sulama Birliği alanları (Şekil 1) çalışma materyali olarak alınmıştır. Adı geçen sulama birliklerinin seçilmesinin temel nedeni; bu birliklerin yapısal olarak birçok yönüyle benzerlik göstermesi ve bu durumun karşılaştırmalı değerlendirme uygulaması için uygun bir zemin oluşturmasıdır.

Denizli, Aydın, Muğla, Uşak ve Afyon illerini kapsayan ve geniş bir alanı temsil etmekte olan Büyük Menderes Havzası 24976 km² lik bir alana sahiptir. Başlıca akarsuyu Büyük Menderes Nehri olan havza, Ege Bölgesi'nin güneybatı kesiminde yer alır. Yazları sıcak ve kurak, kışları ılıman ve yağışlı karakterde tipik Akdeniz iklimi özellikleri gösteren havzada, uzun yıllar yağış ortalaması $648.9 \mathrm{~mm}$, uzun yıllar sicaklık ortalaması ise 17.6 ${ }^{\circ} \mathrm{C}$ 'dir. Havzanın hâkim bitki desenini, endüstri bitkileri oluşturmaktadır (Akçay, 2007).

Türkiye'nin batısında yer alan ve Menemen Sağ ve Sol Sahil Sulama Birliği'ni de sınırları içerisinde barındıran Gediz Havzası 17220 km² lik bir alana sahiptir. Bölgenin sahil kesimlerinde yazları sıcak ve kurak, kışları ılık ve yağışlı geçen Akdeniz iklimi etkendir. İç kesimlerde ise yumuşak bir karasal iklim gözlenmektedir. Bölgenin yıllık ortalama yağışı $626 \mathrm{~mm}$ ve yıllık ortalama sıcaklığı $15.6{ }^{\circ} \mathrm{C}$ 'dir. Havzada yaygın olarak pamuk, tahıl, üzüm, sebze ve meyveler, 
zeytin, tütün ve bostan yetiştirilmektedir (Anaç ve ark., 2008).
Araștırmada ele alınan sulama birliklerinin bazı özellikleri ise Tablo 1'de verilmiştir.

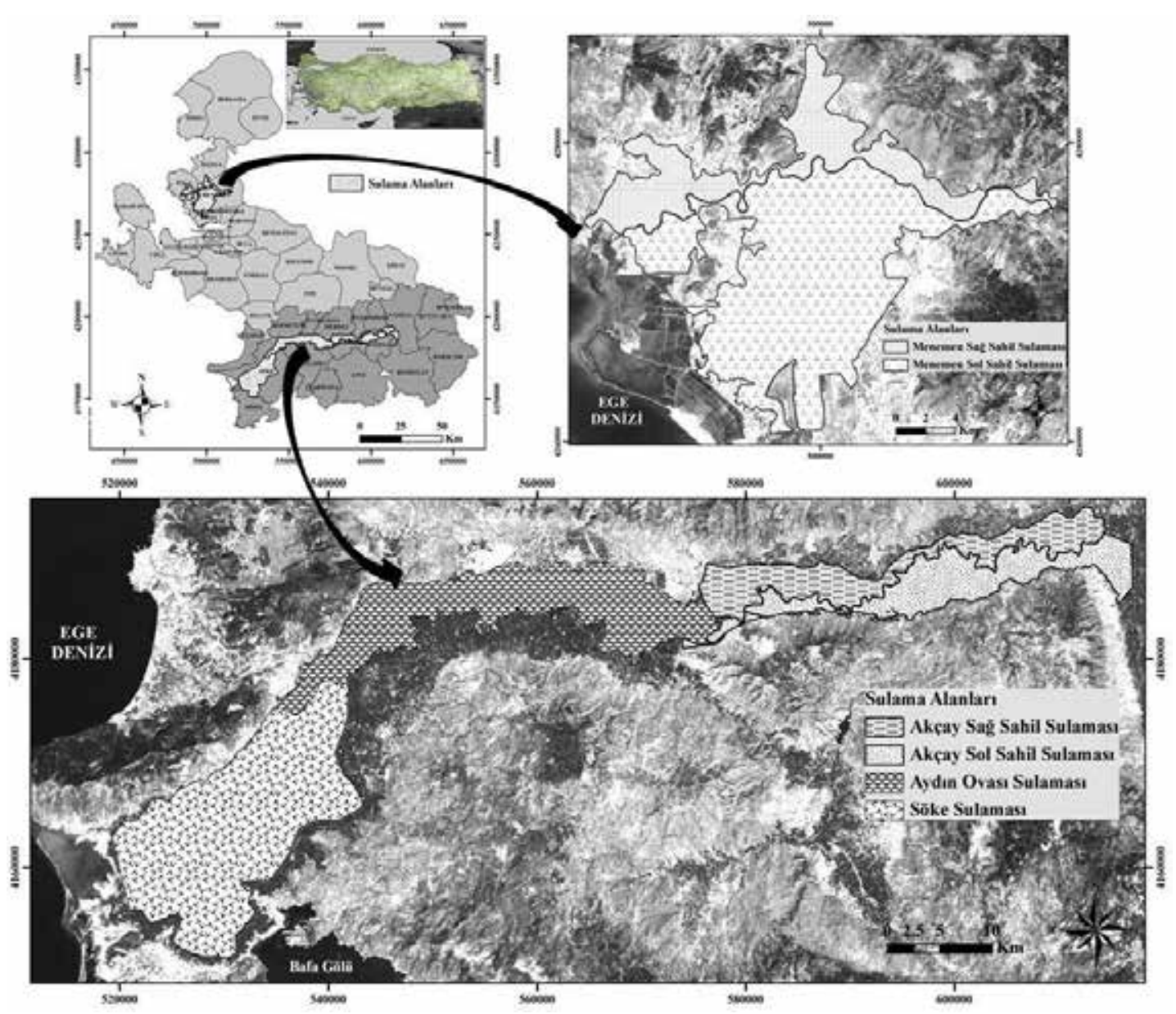

Şekil 1. Çalışmada ele alınan sulama birliklerinin konumu

Tablo 1. Çalışma kapsamında incelenen sulama birliklerine ilişkin bazı tanıtıcı özellikler

\begin{tabular}{|c|c|c|c|c|c|c|}
\hline Özellikler & $\begin{array}{c}\text { Akçay Sağ } \\
\text { SSB }\end{array}$ & $\begin{array}{c}\text { Akçay Sol } \\
\text { SSB }\end{array}$ & $\begin{array}{c}\text { Aydın Ovas } 1 \\
\text { SB }\end{array}$ & $\begin{array}{c}\text { Söke Ovas1 } \\
\text { SB }\end{array}$ & $\begin{array}{c}\text { Menemen } \\
\text { Sağ SSB }\end{array}$ & $\begin{array}{c}\text { Menemen } \\
\text { Sol SSB }\end{array}$ \\
\hline Devir tarihi & 1995 & 1995 & 1998 & 1998 & 1995 & 1995 \\
\hline Net sulama alanı (ha) & 8680 & 6220 & 15000 & 26000 & 6365 & 16500 \\
\hline Başlıca ürün & Pamuk & Pamuk & Pamuk & Pamuk & Pamuk & Pamuk \\
\hline Depolama tesisi & $\begin{array}{l}\text { Kemer } \\
\text { Baraj1 }\end{array}$ & $\begin{array}{l}\text { Kemer } \\
\text { Baraj1 }\end{array}$ & $\begin{array}{l}\text { Kemer ve } \\
\text { Adıgüzel } \\
\text { Barajları }\end{array}$ & $\begin{array}{l}\text { Kemer ve } \\
\text { Adıgüzel } \\
\text { Barajları }\end{array}$ & $\begin{array}{c}\text { Demirköprü } \\
\text { Baraj1 }\end{array}$ & $\begin{array}{c}\text { Demirköprü } \\
\text { Barajı }\end{array}$ \\
\hline Su kaynağ1 & Akçay & Akçay & $\begin{array}{c}\text { Büyük } \\
\text { Menderes }\end{array}$ & $\begin{array}{c}\text { Büyük } \\
\text { Menderes }\end{array}$ & Gediz Nehri & Gediz Nehri \\
\hline Sulama şekli & Cazibe & Cazibe & $\begin{array}{l}\text { Cazibe } \\
\text { Pompaj }\end{array}$ & Cazibe & Cazibe & Cazibe \\
\hline
\end{tabular}

\subsection{Araștırmada kullanılan performans göstergeleri}

Çalışmada ele alınan 6 adet sulama birliğinin 2000-2009 yılları arasındaki etkinlikleri; Malano ve Burton (2001)'de yer alan karşılaştırmalı değerlendirme (benchmarking) gösterge setinden seçilen göstergeler ile, Molden ve ark. (1998)'den seçilen toplam 7 adet etkinlik göstergesi kullanılarak 2 grup altında değerlendirilmiştir. Bu göstergelerin hesaplanmasında izlenen aşamalar aşağıda verilmiştir. 


\subsubsection{Bitkisel üretim etkinliği göstergeleri}

Bitkisel üretim etkinliğinin belirlenmesinde Eşitlik 1, 2, 3 ve 4 kullanılmıştır.

$$
\mathrm{EBÜD}_{\mathrm{p}}=\frac{\mathrm{EBÜD}}{\mathrm{SA}}
$$

Eşitlikte, EBÜD $\mathrm{p}_{\mathrm{p}}$, proje alanı eşdeğer bitkisel üretim değerini ( $\left.\$ \mathrm{ha}^{-1}\right)$; EBÜD, eşdeğer bitkisel üretim değerini (\$); SA, sulama alanını (ha) ifade etmektedir.

$$
\mathrm{EBÜD}_{\mathrm{S}}=\frac{\mathrm{EBÜD}}{\mathrm{FSA}}
$$

Eşitlikte, EBÜD , sulanan alan eşdeğer bitkisel üretim değerini ( $\left.\$ \mathrm{ha}^{-1}\right)$; EBÜD, eşdeğer bitkisel üretim değerini (\$); FSA, fiilen sulanan alanı (ha) ifade etmektedir.

$$
\mathrm{EBÜD}_{\mathrm{SS}}=\frac{\mathrm{EBÜD}}{\mathrm{SSM}}
$$

Eşitlikte, EBÜD ${ }_{\text {ss, }}$, saptırılan birim su hacmine karşıllk eşdeğer bitkisel üretim değerini $\left(\$ \mathrm{~m}^{-3}\right)$; EBÜD, eşdeğer bitkisel üretim değerini (\$); SSM, sisteme ana kanal bazında saptırılan su miktarını $\left(\mathrm{m}^{3}\right)$ ifade etmektedir.

$$
\mathrm{EBÜD}_{\mathrm{ET}}=\frac{\mathrm{EBÜD}}{\mathrm{ET}}
$$

Eşitlikte, EBÜD ${ }_{\mathrm{ET}}$, tüketilen birim su hacmine karşılık eşdeğer bitkisel üretim değerini $\left(\$ \mathrm{ha}^{-1}\right)$; EBÜD, eşdeğer bitkisel üretim değerini (\$); ET, alanda yetiştirilen bitkiler tarafindan tüketilen toplam su hacmini $\left(\mathrm{m}^{3}\right)$ ifade etmektedir.

Bitkisel üretim değerlerinin hesaplanmasında, Eşdeğer Brüt Üretim Değeri (EBÜD) kullanılmıștır. $\mathrm{Bu}$ değerin elde edilmesinde, araştırma alanı bitki deseninde yer alan her bir bitkinin verimi, ekiliş alanı ve yerel fiyatı, araştırma alanında yetiştirilen ve uluslararası piyasada ticari değeri olan baz ürünün (araştırmada baz ürün olarak pamuk bitkisi alınmıştır) dünya fiyatı kullanılmıştır. Tüm bu veriler Eşitlik 5'e göre hesaplanarak EBÜD elde edilmiştir (Molden ve ark., 1998).

$$
E B \ddot{U} D=\left(\sum_{b i t k i} A i Y i \frac{P i}{P b}\right) * P_{d}
$$

Eşitlikte, Ai, i bitkisinin ekiliş alanı; Yi, i bitkisinin verimi; $\mathrm{Pi}$, i bitkisinin yerel fiyat1; $\mathrm{Pb}$, baz bitkinin yerel fiyatı; $\mathrm{P}_{\mathrm{d}}$, baz bitkinin ortalama dünya fiyatıdır.

Çalışmada kullanılan bitki ekim alanı ve verim değerleri, şebekeye saptırılan sulama suyu miktarı ve ürünlerin yerel fiyatı Devlet $\mathrm{Su}$ İşleri (DSI) kayıtlarından (Anonim, 2000-2009a, Anonim, 2000-2009b) alınmıştır. Bitki su tüketiminin belirlenmesinde kullanılan iklim verileri ise Devlet Meteoroloji İşleri Genel Müdürlüğü kayıtlarından (Anonim, 2000-2009c) elde edilmiştir.

\subsubsection{Su kullanımı etkinliğine ilişkin göstergeler}

$\mathrm{Su}$ kullanımın etkinliğinin belirlenmesinde Eşitlik 6, 7 ve 8 kullanılmıştır.

$$
\mathrm{SSO}=\frac{\mathrm{SKSM}+\mathrm{Y}}{\mathrm{ET}}
$$

Eşitlikte, SSO, su sağlama oranını; SKSM + Y, sulamada kullanılan su miktarı ve yağış toplamını (mm); ET, alanda yetiştirilen bitkiler tarafindan tüketilen su miktarını $(\mathrm{mm})$ ifade etmektedir.

$$
\mathrm{SSSO}=\frac{\mathrm{SKSM}}{\mathrm{SSG}}
$$

Eşitlikte, SSSO, sulama suyu sağlama oranını; SKSM, sulamada kullanılan su miktarını (mm); SSG, sulama suyu gereksinimini (mm) ifade etmektedir.

$$
\mathrm{BSADS}=\frac{\mathrm{SSM}}{\mathrm{FSA}}
$$

Eşitlikte, BSADS, birim sulanan alana düşen su miktarını $\left(\mathrm{m}^{3} \mathrm{ha}^{-1}\right)$; SSM, sisteme ana kanal bazında saptırılan su miktarını $\left(\mathrm{m}^{3}\right)$; FSA, fiilen sulanan alanı (ha) ifade etmektedir.

Sulama sistemine saptırılan su miktarı ve sulama suyu gereksiniminin belirlenmesinde kullanılan veriler, ilgili sulama birliklerinin "İzleme ve Değerlendirme Raporları"ndan alınmıştır (Anonim, 2000-2009d). Çalışmada kullanılan bitki su tüketimi ve sulama suyu gereksinimi değerleri CROPWAT yazılımı (Smith, 1992) kullanılarak; Aydın, Söke ve Menemen Meteoroloji İstasyonları'nın kayıtları dikkate alınarak her üretim sezonu için ayrı ayrı hesaplanmıştır. Yazılım yardımıyla PenmanMonteith yöntemine göre referans bitki su tüketimi ve sulama suyu gereksinimleri hesaplanmıştır. Sistem sulama suyu gereksiniminin hesaplanmasında birliklerde yıllara göre değişen bitki deseni göz önüne alınmıştır. Sulama randımanı değerleri ile ilgili veriler genel sulama planlarından alınmıştır (Anonim, 2000-2009e).

\section{Bulgular ve Tartışma}

\subsection{Bitkisel üretim etkinliği değerlendirmeleri}

Çalışmada ele alınan 6 adet sulama birliğinde, 4 farklı bitkisel üretim etkinlik göstergesi 
kullanılarak 2000-2009 yılları için yapılan değerlendirme sonuçları Tablo 2'de verilmiştir.

\subsubsection{Proje alanı bitkisel üretim değeri}

Sulama projelerinde sulanması öngörülen alanlardan elde edilen bitkisel üretim değerleri incelendiğinde; Menemen Sağ Sahil Sulama Birliği ve Sol Sahil Sulama Birliği ile Akçay Sağ Sahil Sulama Birliği'nin ortalama üretim değerlerinin daha yüksek düzeyde gerçekleştiği, ancak özellikle Akçay Sol Sahil Sulama Birliği ve Aydın Ovası Sulama Birliği'nde daha düşük üretim değerlerinin elde edildiği belirlenmiştir. Çalışmada proje alanı bitkisel üretim ortalama değeri 1707-2824 \$ ha ${ }^{-1}$ aralığında değişim göstermiştir. $\mathrm{Bu}$ durum; ilgili göstergenin değerinin sulama oranı, sulama alanındaki bitki yoğunluğu, baz bitkinin yerel piyasadaki ve dünya piyasalarındaki fiyatı ve incelenen ürünün verimine bağlı olarak değişmesinden kaynaklanmaktadır. Yüksek üretim değerine sahip olan sulama birliklerinin bitki desenlerinde meyve, bağ ve çilek gibi ekonomik değeri yüksek bitkilerin yetiştiriciliğinin var olması da önemli bir unsurdur. Üretim değerleri düşük olarak gerçekleşen diğer sulama birliklerinin ürün deseninde yörede uzun yıllardır tarımı yapılan ancak ekonomik değeri nispeten düşük olan pamuk, ana ürün misır ve ikinci ürün misır bitkilerinin bulunması, bitkisel üretim değerlerinin düşüklüğüne bir açıklama getirebilir. Yine Batı Ege'nin aşağı havzalarında yetiştirilen hakim bitki olan pamuk bitkisinin yerel ve dünya pazarlarındaki fiyatının düşük seyretmesi de üretim değerlerinin düşük olmasına neden olmaktadır.

Sakthivadivel ve ark. (1999), Türkiye'deki 6 sulama sisteminde proje alanı bitkisel üretim değerinin 1329-2526 \$ ha ${ }^{-1}$ arasında; Değirmenci (2004), dört sulama şebekesinde proje alanı bitkisel üretim değerinin 430-2573 $\$ \mathrm{ha}^{-1}$ aralığında değiştiğini belirlemiştir. Ülkemizde yapılan diğer çalışmalarda proje alanı bitkisel üretim değeri; Avcı ve ark. (1998) tarafindan Bergama-Kestel sulama birliği için $3523 \$$ ha $^{-1}$; Şener ve ark. (2007) tarafindan Hayrabolu sulama sistemi için $709 \$$ ha $^{-1}$; Çakmak (2001) tarafindan, Konya sulama birlikleri için 195-5391 \$ ha ${ }^{-1}$ arasında; Değirmenci (2001) tarafindan Ulubat sulamasında 1070-1583 \$ ha ${ }^{-1}$; Çakmak (2002) tarafindan Kızılırmak Havzası sulama birliklerinde 309-2643 \$ ha ${ }^{-1}$; Çakmak ve ark. (2009) tarafından Asartepe sulama birliğinde 1979-2262 \$ ha ${ }^{-1}$ arasında; Akkuzu ve Pamuk Mengü, (2011) tarafından Alaşehir sulama birlikleri için 2450$3709 \$$ ha $^{-1}$ arasında değiştiği belirlenmiştir. Çalışmada ele alınan sulama birliklerinden elde edilen değerler, benzer çalışma sonuçları ile karşılaştırıldığında, proje alanı bitkisel üretim değerinin yüksek olduğu sonucuna varılabilir.

Tablo 2. Çalışmada ele alınan sulama birliklerine ilişkin yıllara göre bitkisel üretim etkinliği göstergeleri

\begin{tabular}{|c|c|c|c|c|c|c|c|c|c|c|c|c|}
\hline Göste & lama birlikleri & 000 & 2001 & 2002 & 2003 & 2004 & 2005 & 2006 & 2007 & 2008 & 2009 & Ort \\
\hline \multirow{6}{*}{$\begin{array}{l}\text { Proje alan1 } \\
\text { bitkisel } \\
\text { üretim } \\
\text { değeri } \\
\left(\$ \text { ha }^{-1}\right)\end{array}$} & & 754 & 1247 & 381 & 972 & 2531 & 5796 & 297 & 3231 & 3096 & 2930 & 282 \\
\hline & & 97 & 1286 & 423 & 633 & 2255 & 3234 & 441 & 2477 & 2731 & 2990 & 2297 \\
\hline & & 68 & 1162 & 570 & & 2726 & 280 & 030 & 2644 & & 2923 & \\
\hline & & & 1132 & 1430 & & 1339 & 2514 & 332 & & 1504 & & \\
\hline & & 466 & 1135 & 1296 & 1754 & 2063 & 2471 & 2270 & 1213 & 1735 & 1664 & $1 / 0$ \\
\hline & & & 1283 & 580 & 218 & 2114 & 113 & 370 & 1777 & 2650 & 2410 & 200 \\
\hline \multirow{6}{*}{$\begin{array}{l}\text { Sulanan } \\
\text { alan } \\
\text { bitkisel } \\
\text { üretim } \\
\text { değeri } \\
\left(\$ \text { ha }^{-1}\right) \\
\end{array}$} & & 052 & 1747 & 512 & 172 & 2432 & 5766 & 922 & 4070 & 4784 & 4656 & 341 \\
\hline & & 100 & 1632 & 1757 & 2000 & 2478 & 3108 & 401 & 3047 & 3647 & 3556 & 267 \\
\hline & & 514 & 1594 & 2156 & 084 & 3596 & 3020 & 4323 & 5974 & 3818 & 3957 & 341 \\
\hline & & 59 & 1454 & 1829 & 2467 & 2284 & 2785 & 3470 & 3899 & 3320 & 2702 & 262 \\
\hline & & 923 & 1513 & 1727 & 2421 & 2772 & 2073 & 2208 & 1959 & 2554 & 3004 & 221 \\
\hline & & 591 & 1343 & 1637 & 2220 & 2347 & 2236 & 2099 & 1817 & 2778 & 2417 & 204 \\
\hline \multirow{6}{*}{$\begin{array}{l}\text { Saptırılan } \\
\text { birim suya } \\
\text { karşıllk } \\
\text { bitkisel } \\
\text { üretim } \\
\text { değeri }\left(\$ \mathrm{~m}^{-3}\right)\end{array}$} & & & & 0.19 & & 0.42 & 1.0 & 8 & & & & 0.6 \\
\hline & SSB & 0.28 & 0.30 & 0.20 & 0.22 & 0.35 & 0.51 & 0.50 & 1.04 & 1.64 & 0.62 & 0.5 \\
\hline & & 0.21 & 0.14 & 0.19 & 0.28 & 0.29 & 0.26 & 0.32 & 0.79 & 0.51 & 0.33 & 0.3 \\
\hline & & 0.18 & 0.15 & 0.18 & 0.23 & 0.21 & 0.39 & 0.41 & 0.83 & 0.33 & 0.11 & 0.3 \\
\hline & & 0.18 & 0.18 & 0.19 & 0.24 & 0.22 & 0.32 & 0.26 & 0.54 & 0.74 & 0.31 & 0.3 \\
\hline & & & 0.21 & 0.24 & 0.25 & 0.32 & 0.3 & 0.34 & 0.91 & 0.82 & 0.36 & 0.4 \\
\hline \multirow{6}{*}{$\begin{array}{l}\text { Bitki su } \\
\text { tüketimine } \\
\text { karş1lik } \\
\text { bitkisel } \\
\text { üretim } \\
\text { değeri }\left(\$ \mathrm{~m}^{-3}\right)\end{array}$} & & & & & & & & & & 0.60 & 0. & 0.4 \\
\hline & & & & 0.1 & & $0 .$. & $0 .$. & & & 0.62 & 0.64 & 0.4 \\
\hline & & & & 0.28 & 0. & 0.4 & 0. & 年 & & 0.41 & 0.56 & 0.4 \\
\hline & & 0.2 & 0.18 & 0.23 & 0.3 & 0.34 & 0.3 & 0.4 & 0.53 & 0.45 & 0.37 & 0.3 \\
\hline & ydin Ovası SB & 0.27 & 0.21 & 0.22 & 0.37 & 0.44 & 0.39 & 0.37 & 0.32 & 0.44 & 0.51 & 0.3 \\
\hline & & & & 0.20 & 0.32 & 0.25 & 0.33 & 0.31 & 0.27 & 0.39 & 0.26 & 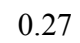 \\
\hline
\end{tabular}




\subsubsection{Sulanan alan bitkisel üretim değeri}

Yapılan değerlendirmeler sonucunda, Menemen Sağ Sahil Sulama Birliği ve Akçay Sağ Sahil Sulama Birliği'nin sulanan alan bitkisel üretim değerlerinin incelenen diğer sulama birliklerine göre daha yüksek olduğu görülmektedir (Tablo 2). Bu göstergenin değerinin yüksek olmasının ana nedeni; her iki sulama birliğinde meyve, bağ ve çilek gibi ekonomik değeri yüksek bitkilerin yetiştiriciliğinin yapılmasıdır. Diğer birliklerde görülen performans düşüklüğünün temel sebebi ise bu birliklerin bitki deseninde pazar fiyatı nispeten düşük olan bitkilerin bulunmasıdır. Ekonomik değeri düşük bitkilerden elde edilen üretim değerleri de düşük olacağından, sulanan alan bitkisel üretim performansı da düşük gerçekleşmiştir.

Sakthivadivel ve ark. (1999), tarafindan 13 ülkede, 40 sulama şebekesinde yürütülen bir çalışmada; sulanan alan bitkisel üretim değerinin 384-3434 \$ ha ${ }^{-1}$ arasında değiştiği saptanmıştır. Yapılan diğer çalışmalarda, sulanan birim alan başına bitkisel üretim değeri; Avcı ve ark. (1998) tarafından Bergama-Kestel sulama birliği için $6223 \$$ ha $^{-1}$; Şener ve ark. (2007) tarafindan Hayrabolu sulama sistemi için 2325 \$ $\mathrm{ha}^{-1}$; Çakmak (2001) tarafından Konya sulama birlikleri için 359-6197 \$ ha ${ }^{-1}$ arasında; Değirmenci (2001) tarafindan Ulubat Sulamasinda 2857-4415 \$ ha ${ }^{-1}$ arasında; Çakmak (2002) tarafindan Kızılırmak Havzası sulama birlikleri için 516-6540 \$ ha ${ }^{-1}$ arasında; Çakmak ve ark. (2009) tarafindan Asartepe sulama birliği için 3534-4930 \$ ha ${ }^{-1}$ arasında; Akkuzu ve Pamuk Mengü, (2011) tarafından Alaşehir yöresinde yer alan sulama birlikleri için 5856-5937 $\$$ ha $^{-1}$ arasında değiştiği belirlenmiştir.

Çalışma sonucunda incelenen birliklerde ortalama 2048-3411 $\$$ ha $^{-1}$ sulanan alan bitkisel üretim değerinin elde edildiği saptanmıştır. $\mathrm{Bu}$ sonuçlar Türkiye'de benzer nitelikte sulama birliklerinde yürütülen çalışmalarla karşılaştırıldığında, Aşağı Büyük Menderes ve Aşağı Gediz Havzası sulama birliklerinin performansının iyi durumda olduğu söylenebilmektedir.

\subsubsection{Saptırılan birim suya karşılık bitkisel üretim değeri}

Akçay, Aydın Ovası, Söke Ovası ve Menemen Sulama Birliği'nde değerlendirilen dönem (20002009) için belirlenen saptırılan birim suya karşılık bitkisel üretim değerleri Tablo 2'de verilmiştir.

Tablo 2'nin incelenmesinden de görülebileceği gibi, ilgili göstergenin ortalama değeri sulama birliklerine göre $0.30-0.60 \$ \mathrm{~m}^{-3}$ arasında değişmektedir. Özellikle Menemen Sağ ve Sol Sahil Sulama Birlikleri'nde şebekeye alınan birim sudan çok daha yüksek bir etkinlikle yararlanıldığ görülmektedir. Aşağı Büyük Menderes Havzası'nda yer alan sulama birliklerinin ortalama değerleri birbirine yakın görünmekle birlikte, en yüksek değer Söke Ovası Sulama Birliği'nden elde edilmiştir. Adı geçen üç sulama birliğinin de Aşağ 1 Gediz ve Aşağı Büyük Menderes Havzaları'nın mansap su kullanıcısı olduğu bilinmektedir. Mansap su kullanıcılarının genellikle daha az suyla yetinme zorunlulukları kaçınılmaz bir gerçek olduğu için, adı geçen üç sulama birliğinde daha az suyla daha etkin bir sulama yönetiminin gerçekleştirildiği söylenebilir. Bunun yanında özellikle Söke Ovası Sulama Birliği’nde yaygın bir uygulama olan, drenajdan dönen marjinal suların yeniden sulamada kullanılması işlemi de bu birlikte üretim değerlerinin yüksek olmasına bir diğer açıklama olarak getirilebilir.

Saptırılan birim suya karşılık bitkisel üretim değerlerini; Sakthivadivel ve ark. (1999), 0.04$0.62 \$ \mathrm{~m}^{-3}$ aralığında; Çakmak (2002), Kızılırmak Havzası sulama birliklerinde $0.05-0.59 \$ \mathrm{~m}^{-3}$ aralığında; Kukul ve ark. (2008), Menemen Sulama Sisteminde 0.08-0.73 $\$ \mathrm{~m}^{-3}$ arasında; Akkuzu ve Pamuk Mengü (2011), Alaşehir yöresi sulama birliklerinde $0.42-3.87 \$ \mathrm{~m}^{-3}$ arasinda değiştiğini belirlemiştir.

Çalışma kapsamında değerlendirilen birliklerden elde edilen bulgular, benzer yapıdaki üretim sistemlerinden elde edilen sonuçlarla karşılaştırıldığında, saptırılan birim suya karşılık bitkisel üretim değeri performansının benzer düzeyde olduğu saptanmıştır. Bu durum daha önce de belirtildiği gibi özellikle mansapta yer alan sulama sistemlerinde yaşanan su kaynağ yetersizliğinden ileri gelmektedir.

\subsubsection{Bitki su tüketimine karşılık bitkisel üretim değeri}

Kisıtlı bir kaynak olan suyun, tüketilen bir birimine karşılık elde edilen üretim değerinin ne olduğu sorusunun yanıtını nicelleştirmeye yarayan bir performans göstergesi olan bitki su tüketimine karşılık bitkisel üretim değerleri Tablo 2'de verilmiştir. İlgili tablonun incelenmesiyle, tüketilen birim su hacmine karşılık elde edilen üretim değerinin Akçay Sağ Sahil Sulama Birliği'nde en yüksek ortalamaya sahip olduğu görülmektedir. Menemen Sağ ve Sol Sahil Sulama Birliği $0.42 \$ \mathrm{~m}^{-3}$ ortalaması ile yüksek üretim değerlerine sahip diğer sulama birlikleridir. Söke Ovası Sulama Birliği ise tüketilen birim su hacmine karşılık en düşük üretim değerine sahiptir. $\mathrm{Bu}$ parametre bitki çeşidi ve iklim faktörlerine bağlı olarak değişim göstermektedir. Söke Ovası 
Sulama Birliği, sulama alanında fazla su tüketen bitkilerin yetiştiriciliğinin yoğun olarak yapılmasının yanında, yöresel iklim faktörleri açısından da bitki su tüketimini arttıracak iklim özelliklerine sahip olması nedeniyle, üretim değerleri $0.27 \$ \mathrm{~m}^{-3}$ ortalaması ile en düşük düzeyde gerçekleşmiştir.

Molden ve ark. (1998) tarafindan yapılan bir çalışmada; tamamen çeltik yetiştiriciliği yapılan ve su kaynağı bol olan şebekelerle, yine çeltik tarımı yapılan ve bitki yoğunluğu \% 100'den daha düşük olan şebekelerde üretim değerinin $0.10 \$ \mathrm{~m}^{-3}$ düzeyinde olduğu belirlenmiştir. Su kaynağının yetersiz olduğu, meyve ve endüstri bitkileri yetiştiriciliği yapılan şebekelerle pompaj sulaması yapılan şebekelerde ise üretim değerinin 0.20-0.60 $\$ \mathrm{~m}^{-3}$ aralığında değiştiğgi belirtilmiştir. Merdun (2004), ise 2001 y1lı için Türkiye'deki 239 şebekede tüketilen birim suya karşılık bitkisel üretim değerinin $0.14-1.47 \$ \mathrm{~m}^{-3}$ arasında değiştiğini belirlemiştir.

\subsection{Su kullanım etkinliği değerlendirmeleri}

Çalışmada ele alınan 6 adet sulama birliğinde, 3 farklı su kullanım etkinliği göstergesi kullanılarak, 2000-2009 yılları için yapılan değerlendirme sonuçları Tablo 3 'te verilmiştir.

\subsubsection{Su temini oranı}

$\mathrm{Su}$ temini oranı sulama alanında bitkilerin ihtiyaç duyduğu su miktarının ne kadarının karşılanabildiğini ifade eder. Çalışma kapsamındaki sulama birliklerine ilişkin su sağlama oranı değerlerinin 2000-2009 yılları arasındaki değişimi Tablo 3'te verilmiştir. Değerler 0.47 ile 2.02 arasında değişmekte olup, ortalama değerler de 1.02-1.60 değerleri arasındadır. Havzada yaşanan kurak dönemi kapsayan 2007 ve 2008 yıllarında, birliklerde daha düşük su temini oranları belirlenmiştir.

Sulama sistemlerinde su sağlama göstergelerinin belirlenmesine yönelik olarak IWMI tarafından yapılan çalışmalarda, belirlenen su temini oranı 0.8 ile 4 arasında değişmekte olup, sistemlerin çoğunda saptırılan suyun yeterli olduğunu gösteren oran 2'den büyüktür (Molden ve ark.,1998). Levine (1982), şebekelere verilen suyun, net sulama suyu gereksiniminin 2.5 katından fazla olmasinın uygun olmayan su yönetiminin bir göstergesi olduğunu belirtmiştir.

Çakmak (2002), Kızılırmak Havzası sulama birliklerinde su sağlama oranı değerini 1.58 ile 4.81 değerleri arasında belirlemiş; Mengü ve Akkuzu (2010), Gediz Havzası sulama birliklerinde yürüttükleri çalışmada, su sağlama oranı değerinin 0.88-1.49 aralığında; Kukul ve ark. (2008) Menemen sulama sisteminin devir öncesi ve devir sonrası performansını değerlendirdiği çalışmada, su sağlama oranını devir öncesi 1.33, devir sonrası ise 1.01 olarak belirlemiştir. Şener (2011), DSİ XI. Bölgesi'nde yer alan 10 adet sulama sisteminin su sağlama oranını belirlediği çalışmada, değerlerin 0.45-6.28 aralığında değişism gösterdiğini saptamıştır.

Tablo 3. Çalışmada ele alınan sulama birliklerine ilişkin yıllara göre su kullanım etkinliği göstergeleri

\begin{tabular}{|c|c|c|c|c|c|c|c|c|c|c|c|c|}
\hline Gösterge & Sulama birlikleri & 2000 & 2001 & 2002 & 2003 & 2004 & 2005 & 2006 & 2007 & 2008 & 2009 & Ort. \\
\hline \multirow{6}{*}{$\begin{array}{l}\mathrm{Su} \\
\text { sağlama } \\
\text { oranı }\end{array}$} & Menemen Sağ SSB & 1.83 & 0.86 & 1.39 & 1.28 & 1.81 & 1.04 & 1.27 & 0.99 & 0.63 & 1.17 & 1.23 \\
\hline & Menemen Sol SSB & 1.18 & 0.79 & 1.51 & 1.52 & 1.99 & 1.32 & 1.31 & 0.61 & 0.47 & 1.23 & 1.19 \\
\hline & Akçay Sağ SSB & 1.57 & 1.41 & 1.63 & 1.54 & 1.62 & 1.96 & 2.02 & 1.14 & 1.22 & 1.84 & 1.60 \\
\hline & Akçay Sol SSB & 1.23 & 1.14 & 1.37 & 1.28 & 1.55 & 1.12 & 1.29 & 0.72 & 1.54 & 1.94 & 1.32 \\
\hline & Aydın Ovası SB & 1.22 & 1.11 & 1.23 & 1.38 & 1.82 & 1.78 & 1.98 & 0.88 & 0.77 & 2.07 & 1.42 \\
\hline & Söke Ovası SB & 0.76 & 0.75 & 0.90 & 1.03 & 0.68 & 1.68 & 1.71 & 0.55 & 0.89 & 1.22 & 1.02 \\
\hline \multirow{6}{*}{$\begin{array}{l}\text { Sulama } \\
\text { suyu } \\
\text { sağlama } \\
\text { oranı }\end{array}$} & Menemen Sağ SSB & 1.19 & 0.53 & 0.91 & 0.85 & 1.15 & 0.69 & 0.89 & 0.65 & 0.39 & 0.80 & 0.83 \\
\hline & Menemen Sol SSB & 0.79 & 0.49 & 0.94 & 0.95 & 1.30 & 0.86 & 0.85 & 0.37 & 0.29 & 0.78 & 0.76 \\
\hline & Akçay Sağ SSB & 0.89 & 0.80 & 0.93 & 0.88 & 0.92 & 1.32 & 1.42 & 0.71 & 0.79 & 1.21 & 0.95 \\
\hline & Akçay Sol SSB & 0.72 & 0.65 & 0.78 & 0.73 & 0.89 & 0.73 & 0.86 & 0.47 & 1.00 & 1.22 & 0.81 \\
\hline & Aydın Ovası SB & 0.70 & 0.63 & 0.70 & 0.79 & 1.04 & 1.10 & 1.26 & 0.53 & 0.49 & 1.30 & 0.83 \\
\hline & Söke Ovası SB & 0.43 & 0.43 & 0.51 & 0.59 & 0.39 & 1.11 & 1.07 & 0.34 & 0.54 & 0.79 & 0.62 \\
\hline \multirow{6}{*}{$\begin{array}{l}\text { Birim } \\
\text { sulanan } \\
\text { alana } \\
\text { düşen su } \\
\text { miktar1 } \\
\left(\mathrm{m}^{3} \mathrm{ha}^{-1}\right)\end{array}$} & Menemen Sağ SSB & 5874 & 4580 & 8155 & 7599 & 5751 & 5345 & 7442 & 7089 & 3088 & 8141 & 6306 \\
\hline & Menemen Sol SSB & 6709 & 5389 & 8730 & 8993 & 7112 & 6048 & 6732 & 2908 & 2217 & 6144 & 6098 \\
\hline & Akçay Sağ SSB & 12649 & 11456 & 11310 & 11177 & 12119 & 11589 & 13413 & 7516 & 7414 & 11789 & 11043 \\
\hline & Akçay Sol SSB & 11756 & 9847 & 10157 & 10601 & 10827 & 7177 & 9102 & 5053 & 9848 & 25149 & 10952 \\
\hline & Aydın Ovası SB & 10701 & 8617 & 9024 & 10265 & 12814 & 6472 & 8665 & 3588 & 3449 & 9537 & 8313 \\
\hline & Söke Ovası SB & 6422 & 6485 & 6957 & 9001 & 5495 & 6971 & 6181 & 1977 & 3374 & 6786 & 5965 \\
\hline
\end{tabular}


Tüm birlikler bazında genel bir değerlendirme yapılacak olursa; özellikle Söke Ovası Sulama Birliği'nde en düşük su temini oranları saptanmıştır. $\mathrm{Bu}$ durum, su depolamadaki yetersizlikler veya sezon öncesi yapılan genel sulama planlarına uyulamaması nedeniyle, mansap su kullanıcısı olan Söke Ovası Sulama Birliği'nde sulama şebekesine planlanandan daha az su saptırılmasindan kaynaklanmaktadır. Değerlendirilen birlikler genelinde yeterli bir su temininden bahsetmek pek mümkün değildir.

\subsubsection{Sulama suyu temini oranı}

Sulama alanının toplam sulama suyu gereksiniminin, sisteme alınan su miktarı ile ne düzeyde karşılanabildiğinin bir göstergesi olan sulama suyu temini oranı değerinin 0.62-0.95 arasında değiştiği ve çalışma alanı kapsamındaki tüm sistemlerde optimum değer olan 1'in altında kaldığ1 görülmektedir (Tablo 3). $\mathrm{Bu}$ durum şebekelerde su sağlamadaki yetersizliği ifade etmektedir. Ele alınan altı sulama birliği arasında, göreceli olarak en yüksek sulama suyu temini oranına sahip olan Akçay Sağ Sahil Sulama Birliği 0.95 ortalama değeri ile optimum değer olan 1.00 'a en yakın düzeyde görünmektedir. Bu durum irdelenen sulama birlikleri arasında en iyi su temini düzeyinin Akçay Sağ Sahil Sulama Birliği'nde gerçekleştiğini ifade etmektedir. İncelenen tüm sulama birlikleri arasında, sulama suyu temini oranı açısından en düşük değerler Söke Ovası Sulama Birliği’nde belirlenmiştir. Bu durumun en temel nedeni Söke Ovası Sulama Birliği'nin Aşağı Büyük Menderes Havzası'nın mansabında bulunmasından ve üst kullanıcılardan arta kalan suyun bu alana yetersiz gelmesinden kaynaklanmaktadır.

Beyribey (1997) tarafından bir çalışmada; devlet sulama şebekelerinde 1984-1993 y1lları için toplam su sağlama oranı 50 şebekede 1 'den küçük, 64 şebekede 1-2 arasında ve 6 şebekede 2'den büyük olduğu saptanmıştır. Sulama suyu sağlama oranının 1'e eşit olması sulama şebekesine gereksinim duyulduğu kadar su saptırıldığını, 1 'den az olması yetersiz su sağlandığını, 1'den büyük olması ise sulama şebekesine gereğinden fazla su saptırıldığını gösterir. Değirmenci (2001), Türkiye genelinde devredilen 158 sulama şebekesinde şebeke ihtiyacının 2-7 kat arasında (sulama suyu sağlama oranı 0.91-7.15) daha fazla su alındığını belirlemiştir. Merdun (2004), Türkiye'de yer alan 239 sulama şebekesinde 2001 yılı için sulama suyu sağlama oranının 1.41-4.04 arasında değiştiğini belirlemiş ve şebekelere sağlanan sulama suyunun gereksinimden fazla olduğu, yani şebekelerde etkin ve uniform bir su dağıtımının gerçekleştirilemediği sonucuna varmıştır.

Çalışma kapsamında elde edilen sonuçlar daha önce yapılmış çalışma sonuçları ile karşılaştırıldığında, incelenen sulama birliklerine yetersiz su sağlandığı görülmektedir. Mansap su kullanıcısı birliklerin de yeterli sulama suyunu alabilmeleri için genel sulama planlarına uyulması ve uygun bir su dağıtımının yapılması, su kullanıcılar arasında adil ve eşit bir su paylaşımının sağlanması açısından önemli bir gerekliliktir.

\subsubsection{Birim sulanan alana düşen su miktarı}

Tablo 3 incelendiğinde; ele alınan sulama birlikleri arasında en yüksek birim sulanan alana düşen su miktarı değeri Akçay Sağ Sahil Sulama Birliği'nde, en düşük değer ise Söke Ovası Sulama Birliği'nde belirlenmiştir. Orta havzada yer alan Aydın Ovası Sulama Birliği'nde $8313 \mathrm{~m}^{3} \mathrm{ha}^{-1} \mathrm{su}$ kullanılırken, gerek Gediz Havzası'nın mansabında yer alan Menemen Sağ Sahil Sulama Birliği, gerekse de Aşağı Büyük Menderes Havzası'nın mansabında yer alan Söke Ovası Sulama Birliği'ne sulama sezonu boyunca daha düşük miktarlarda su sağlanması sonucunda birim sulanan alana düşen su miktarları da daha az olmuştur. Yıllar bazında ortalamalar değerlendirildiğinde; 2007 ve 2008 yıllarında yaşanan kuraklıklar tüm sulamalarda kullanılan su miktarlarının oldukça düşük gerçekleşmesine neden olmuştur.

\section{Sonuçlar}

Bu çalışmada Aşağı Büyük Menderes ve Aşağı Gediz Havzaları'nda yer alan altı sulama birliğinin performansı 10 yıllık bir süreç için karşılaştırmalı performans değerlendirme göstergeleri kullanılarak incelenmiştir.

Aşağı Gediz ve Aşağı Büyük Menderes Havzası sulama birliklerinde bitkisel üretim değerleri incelendiğinde, benzer sulama sistemlerine oranla yüksek düzeyde üretim değerlerinin gerçekleştiği belirlenmiştir. Bu sonuç çalışma sahasındaki birliklerde ticari değeri yüksek ürünlerin yetiştirilmesinden kaynaklanmaktadır.

Çalışmada ele alınan altı sulama birliğinde su kullanım etkinliğine ilişkin yapılan değerlendirmeler sonucunda, membadan mansaba doğru gidildikçe birliklerde su temininde olumsuzlukların ortaya çıktığı görülmektedir. Gerek su sağlama ve sulama suyu sağlama oranları, gerekse de sulanan alan başına düşen su miktarları incelendiğinde; Söke Ovası Sulama Birliği'nde oldukça düşük değerlerin gerçekleştiği, 
buna karşılık havzanın görece üst kesiminde yer alan sulama birliklerinde ise daha yüksek su kullanım değerlerine ulaşıldığ 1 görülmektedir. Bu durum kuraklık vb. olumsuz iklim koşulları dışında, sezon öncesi yapılan sulama planlamalarına gereğince uyulmadığını göstermektedir.

$\mathrm{Su}$ teminine ilişkin olarak yaşanan olumsuzlukların en aza indirilebilmesi ve havzalarda memba-mansap su kullanıciları arasında adil su paylaşımının sağlanması, sezon öncesi yapılan genel sulama planlarına uyulması ile mümkün olacaktır. Böylelikle arazi-su verimliliğinde sağlanacak artışlar ile beklenen fayda elde edilerek, kırsal kesimde yaşayan toplumun refahı arttırılabilecektir.

\section{Teşekkür}

Bu çalışma; Adnan Menderes Üniversitesi, Bilimsel Araştırma Projeleri Birimi tarafından desteklenmiştir (Proje No: ZRF-09009).

\section{Kaynaklar}

Akçay, S.M., 2007. Aşağı Büyük Menderes Havzası sulama şebekelerinin devir sonrası performanslarının belirlenmesi. Doktora tezi, Ege Üniversitesi Fen Bilimleri Enstitüsü, İzmir.

Akkuzu, E., Pamuk Mengü, G., 2011. Alaşehir yöresi sulama birliklerinin arazi-su verimliliği ve su temini açısından değerlendirilmesi. Ege Üniversitesi Ziraat Fakültesi Dergisi, 48(2): 119-126.

Anaç, S., Akçay, S., Kukul, Y.S., Taşkın, M., Çiftçi, S.H., 2008. Sulama birliklerine devir sonras1 performans değerlendirmesi: Menemen sulama şebekesi örneği. DSİ 2. Bölge Müdürlüğü Yayınları, İzmir.

Anonim, 2000-2009a. DSİ'ce inşa edilerek işletmeye açılan sulama ve kurutma tesisleri mahsul sayımı sonuçları. DSİ Genel Müdürlüğü Yayınları, Ankara.

Anonim, 2000-2009b. DSI'ce işletilen ve devredilen sulama tesisleri izleme ve değerlendirme raporları. DSİ Genel Müdürlüğü Yayınları, Ankara.

Anonim, 2000-2009c. Devlet Meteoroloji İşleri Genel Müdürlüğü Kayıtları. Ankara.

Anonim, 2000-2009d. Sulama Birlikleri İzleme ve Değerlendirme Raporları. DSİ Genel Müdürlüğü Yayınları, Ankara.

Anonim 2000-2009e. Genel Sulama Planlama Raporları. DSİ Genel Müdürlüğü Yayınları, Ankara.

Avcı, M., Akkuzu, E., Ünal, H.B., Aşık, Ş., 1998. Bergama-Kestel Baraj sulamasi performansının değerlendirilmesi. Ege Bölgesi 1. Tarım Kongresi, Bildiriler Kitabı, Cilt: 2, 7-11 Eylül, Aydın, s. 62-69.

Beyribey, M., 1997. Devlet sulama şebekelerinde sistem performansının değerlendirilmesi. Ankara Üniversitesi Ziraat Fakültesi Yayınları, Yayın No: 1480, Bilimsel Araştırma ve İncelemeler, Ankara.
Bos, M.G., 1997. Performance indicators for irrigation and drainage. Irrigation and Drainage Systems, 11: 119-137.

Çakmak, B., 2001. Konya sulama birliklerinde sulama performansının değerlendirilmesi. Tarım Bilimleri Dergisi, 7(3): 111-117.

Çakmak, B., 2002. Kızılırmak Havzası sulama birliklerinde sulama sistem performansinın değerlendirilmesi. Kahramanmaraş Sütçü İmam Üniversitesi Fen ve Mühendislik Dergisi, 5(2): 130141.

Çakmak, B., Polat, H.E., Kendirli, B., Gökalp, Z., 2009. Evaluation of irrigation performance of Asartepe Irrigation Association: A Case Study from Turkey. Akdeniz Üniversitesi Ziraat Fakültesi Dergisi, 22(1): 1-8.

Değirmenci, H., 2001. Devredilen sulama şebekelerinin karş1laştırma göstergeleri ile değerlendirilmesi. Uludağ Üniversitesi Ziraat Fakültesi Dergisi, 15: 31-41.

Değirmenci, H., 2004. Kahramanmaraş bölgesinde bazı sulama şebekelerinin karşılaştırma göstergeleri ile değerlendirilmesi. Kahramanmaraşs Sütçü İmam Üniversitesi Fen ve Mühendislik Dergisi, 7(1): 104 110.

Gonzalez, F.J., 2000. Benchmarking for irrigation systems: Experiences and possibilities. IPTRIDFAO-WORLDBANK, Working Group on Performance Indicators and Benchmarking. Report on a Workshop, August 3-4, FAO, Rome, Italy.

Kukul, Y.S., Akçay, S., Anaç, S., Yeşilırmak, E., 2008. Temporal irrigation performance assessment in Turkey: Menemen case study. Agricultural Water Management, 95(9): 1090-1098.

Levine, G., 1982. Relative Water Supply: An Explanatory Variable for Irrigation Systems. Technical Report No. 6. Cornell University, Ithaca, New York, USA.

Malano, H., Burton, M., 2001. Guidelines for Benchmarking Performance in the Irrigation and Drainage Sector. International Programme for Technology and Research in Irrigation and Drainage, FAO, Rome.

Mengü, G.P., Akkuzu, E., 2010. Impact of irrigation management transfer on land and water productivity and water supply in the Gediz Basin, Turkey. Journal of Irrigation and Drainage EngineeringASCE, 136(5): 300-308.

Merdun, H., 2004. Comparison of irrigation performance based on the basin, crop pattern and scheme sizes using external indicators. Turkish Journal of Agriculture and Forestry, 28: 321-331.

Molden, D., Gates, T.K., 1990. Performance measures for evaluation of irrigation water delivery systems. Journal of Irrigation and Water Engineering, 116(6): 804-823.

Molden, D.J., Sakthivadiel, R., Perry, C.J., De Fraiture, C., Kloezen, W.H., 1998. Indicators for comparing performance of irrigated agricultural systems. International Water Management Institute Research Report 20, Colombo-Sri Lanka. 
Murray-Rust, D.H., Snellen, W.B., 1993. Irrigation System Performance Assesment and Diagnosis. Joint IIMI/ILRI/IHEE Publication. International Irrigation Management Institute, Colombo, Sri Lanka.

Rao, P.S., 1993. Review of Selected Literature on Indicators of Irrigation Performance. International Irrigation Management Institute, Colombo, Sri Lanka.

Rodriguez-Díaz, J.A., Camacho Poyato, E., López Luque, R., 2004. Applying benchmarking and data envelopment analysis (DEA) techniques to irrigation districts in Spain. Irrigation and Drainage, 53(2): 135-143.

Sakthivadivel, R., De Fraiture, C., Molden, D.J., Perry, C., Kloezen, W., 1999. Indicators for land and water productivity in irrigated agriculture. International
Journal of Water Resources Development, 15(1/2): 161-179.

Small, L.E., Svendsen, M., 1992. A Framework for Assesing Irrigation Performance. Working Papers on Irrigation Performance 1. International Food Policy Research Institute, Washington, D.C.

Smith, M., 1992. CROPWAT: A Computer Program for Irrigation Planning and Management. FAO, Rome, Italy.

Şener, M., Yüksel, A.N., Konukçu, F., 2007. Evaluation of Hayrabolu irrigation scheme in Turkey using comparative performance indicators. Journal of Tekirdag Agricultural Faculty, 4(1): 43-54.

Sener, M., 2011. Su kullanım performansının değerlendirmesi: DSİ XI. Bölge örneği. Tekirdă̆ Ziraat Fakültesi Dergisi, 8(2): 77-84. 